\title{
Alveolar deflation dynamics before and after lung injury assessed by synchrotron radiation computed tomography
}

\author{
G Perchiazzi ${ }^{1,2^{*}}$, JB Borges ${ }^{2}$, G Hedenstierna $^{3}$, L Porra $^{4}$, L Broche $^{5}$, M Pellegrini ${ }^{1,2}$, A Sindaco ${ }^{1}$, AP Tannoia ${ }^{1}$, \\ S Derosa ${ }^{1}$, FFM Todisco', G Scaramuzzo ${ }^{1}$, A Larsson², S Bayat ${ }^{6}$
}

From ESICM LIVES 2015

Berlin, Germany. 3-7 October 2015

\section{Introduction}

During mechanical ventilation, reduction of expiratory pressure may trigger heterogeneous processes of derecruitment, collapse and overdistension of airspaces. However the relationship of such processes with precise regional location inside the lung has not been fully studied in vivo. Synchrotron Radiation Computed Tomography (SRCT) can provide in vivo regional images of the lung at resolutions higher than conventional CT.

\section{Objective}

To evaluate regional deflation dynamics in healthy $(\mathrm{HC})$ and Acute Respiratory Distress Syndrome (ARDS) conditions.

\section{Methods}

Seven New Zealand rabbits were anesthetized and mechanically ventilated with a tidal volume of $7 \mathrm{ml} / \mathrm{kg}$ and positive end-expiratory pressure (PEEP) $3 \mathrm{cmH}_{2} \mathrm{O}$. We studied airspaces located in three concentric regionsof-interest (ROI): subpleural (SP), peripheral (PE) and core (CO). During expiratory pauses, SRCT scans of the lung were taken at decreasing PEEP levels of 12, 9, 6, 3 and 0 $\mathrm{cmH}_{2} \mathrm{O}$. Then, ARDS model was established by repeated lung lavages followed by ventilator-induced lung injury (by pressure-controlled ventilation with inspiratory pressure of 35 and PEEP $=0 \mathrm{cmH}_{2} \mathrm{O}$ ). SRCT scans at the same decremental PEEP levels were repeated. SRCT images with a spatial resolution of $47.6 \mu \mathrm{m}$ were enhanced by phase contrast algorithms, transformed into binary images, and divided into the above-defined ROIs. Numerosity $(\mathrm{N})$, total area (A), and Area/Numerosity ratio $(\mathrm{A} / \mathrm{N})$ indexes were computed by using the Image Processing Toolbox for MatLab (Mathworks, Natick, USA). Statistical analyses to test differences produced by PEEP and/or location were performed by Student's T-test $(\alpha=0.05)$.

\section{Results}

In $\mathrm{HC}, \mathrm{N}$ and $\mathrm{A}$ decreased with decreasing PEEP, which was more evident in $\mathrm{CO}$. A/N remained stable down to PEEP $9 \mathrm{cmH}_{2} \mathrm{O}$ and then decreased with PEEP. In ARDS, $\mathrm{N}$ and A decreased down to PEEP $6 \mathrm{cmH}_{2} \mathrm{O}$ and then remained stable at subsequent lower PEEP levels. SP, PE and $\mathrm{CO}$ areas exhibited similar behaviors but with different magnitudes. In ARDS, between PEEP 12 and PEEP $6 \mathrm{cmH}_{2} \mathrm{O}, \mathrm{A} / \mathrm{N}$ index behavior evidenced that airspaces dimensions in $\mathrm{CO}$ were stable, but decreased below PEEP $6 \mathrm{cmH}_{2} \mathrm{O}$. At each PEEP level, mean dimensions of airspaces were greater in $\mathrm{CO}$ than in $\mathrm{SP}$ regions.

\section{Conclusions}

In healthy conditions, derecruitment occurred continuously along the decremental PEEP levels. When airspaces were fully inflated, they exhibited a more stable behavior, losing less volume. Reducing PEEP from 9 to $0 \mathrm{cmH}_{2} \mathrm{O}$, derecruitment was proportionally greater in the more inflated airspaces, which were predominantly located in the core regions. In ARDS, loss of gas volume between PEEP 12 and $6 \mathrm{cmH}_{2} \mathrm{O}$ was characterized by an "on-off mechanism" of derecruitment, remaining stable the dimensions of the still open airspaces. This may be related to the higher critical closing pressures and lower compliance of ARDS lungs.

${ }^{1}$ Bari University, Emergency and Organ Transplant, Bari, Italy

Full list of author information is available at the end of the article 


\section{Grants}

The School of Anesthesia, Bari University; The Swedish Research Council; The Heart Lung Fund; The ESRF.

\section{Authors' details}

${ }^{1}$ Bari University, Emergency and Organ Transplant, Bari, Italy. ${ }^{2}$ Uppsala

University, Surgical Sciences, Uppsala, Sweden. ${ }^{3}$ Uppsala University, Medical Sciences, Uppsala, Sweden. ${ }^{4}$ University of Helsinki, Physics, Helsinki, Finland, Finland. ${ }^{5}$ European Synchrotron Radiation Facility, Grenoble, France.

${ }^{6}$ Université de Picardie Jules Verne, Laboratoire Peritox EA-INERIS, Amiens,

France.

Published: 1 October 2015

doi:10.1186/2197-425X-3-S1-A567

Cite this article as: Perchiazzi et al:: Alveolar deflation dynamics before and after lung injury assessed by synchrotron radiation computed tomography. Intensive Care Medicine Experimental 2015 3(Suppl 1):A567.

\section{Submit your manuscript to a SpringerOpen ${ }^{\mathcal{O}}$ journal and benefit from:}

- Convenient online submission

- Rigorous peer review

- Immediate publication on acceptance

- Open access: articles freely available online

- High visibility within the field

- Retaining the copyright to your article 